\title{
A Case Report Based on Watson's Theory of Human Caring Model: Child with Corrosive Esophageal Injury and the Child's Parents
}

\author{
(1) Nazife Gamze Özer Özlü1, (1) Fatma Vural2, (1) Kübra Yasak¹ \\ 1Dokuz Eylül University Institute of Health Sciences; Dokuz Eylül University Faculty of Nursing, Department of Surgical Nursing, İzmir, Turkey \\ 2Dokuz Eylül University Faculty of Nursing, Department of Surgical Nursing, İzmir, Turkey
}

\begin{abstract}
Corrosive esophageal injuries are mostly traumatic in childhood. In this case report, the child suffering from nutritional problems due to corrosive esophageal injury and her parents are discussed according to Watson's Theory of Human Caring Model. It is also intended to set an example for using a model in nursing care in the field of pediatric surgery. Since love and compassion are at the center of this model, it was applied comfortably in the department of pediatric surgery. Because in the department of pediatric surgery, love, compassion, and understanding are shown as well as supporting the child and parents to be operated on. In the case, nursing care was applied over the three basic concepts of the model. The child, mother and father were supported and observed with the caritas processes that started in the preoperative period and continued after the surgery. As a result of the care given and the authentic relationship established according to this model, the satisfaction of the child and her parents increased.
\end{abstract}

Keywords: Child, corrosive esophageal injury, family, nursing care, Watson's Theory of Human Caring Model

\section{Introduction}

Corrosive esophageal injuries are a major health problem worldwide, especially in middle-income countries. The main purpose in the treatment of these injuries is the survival of the child, the prevention of perforation and esophageal stenosis, the preservation of oral nutrition and the continuity of quality of life $(1,2)$. Therefore, nurses should get to the core of children's needs by using nursing models in the care of children with these injuries. They should also establish an authentic and understandable relationship with the patient's parents (3).

Watson's Theory of Human Caring Model, which is one of the nursing models that help nurses to provide this care, defines the basis of nursing care as science and art (3-5). Since love and compassion are at the center of this model, it requires knowing the strengths and weaknesses of individuals and their reactions to events (5-10). In order to achieve all this, this model with three basic concepts

The place and date of scientific meeting: This study was presented as a verbal announcement $37^{\text {th }}$ National Pediatric Surgery Congress and $23^{\text {rd }}$ National Pediatric Surgery Nursing Congress in Ankara, Turkey, on 15-19 October 2019. Also, this study was presented as poster $3^{\text {rd }}$ International 11th National Turkish Surgical and Operating Room Nursing Congress in İzmir, Turkey, on 3-6 October 2019. 
is needed, namely, a transpersonal caring relationship, a caring moment, and caritas processes.

In this case, the problems and care of a 6-year-old girl and her parents who were hospitalized for gastric transposition surgery due to corrosive esophageal injury were evaluated according to Watson's Theory of Human Care Model.

\section{Case Report}

This case report was made in accordance with the CARE Guidelines Checklist.

\section{Case Information and Clinical Findings}

The patient was a girl and she had accidentally drunk drain-cleaner at the age of five. Immediately after the accident, the girl's parents took her to a hospital. She was treated for 45 days in the hospital. Due to respiratory distress, the patient was connected to a mechanical ventilator. In the following days, when she could not be taken off the mechanical ventilator, a tracheostomy was performed. She could not be fed orally because of the stenosis in the long segment of the esophagus. Therefore, enteral feeding started from the gastrostomy. She was dilated nine times in the hospital, but these dilatations failed. Thereupon, her parents applied to the pediatric surgery of a university hospital in another city.

At the age of six, the patient underwent gastric transposition surgery. She was in the intensive care unit for six days after the operation and was monitored for three days with a mechanical ventilator. After being taken off the mechanical ventilator, she suffered from coughing and secretion. An attempt was made to initiate enteral feeding via a jejunostomy followed by oral intake in intensive care. When the child's general condition stabilized, she was brought to the service and was kept under surveillance for 14 days.

\section{Timeline}

This model was started from the moment the child first came to the clinic and continued until her discharge from hospital (Figure 1).

\section{Diagnostic Assessment}

In the perioperative process, chest radiography, laboratory tests (hemogram, biochemistry, coagulation) and blood product preparation were performed.

\section{Therapeutic Intervention}

Nursing care was applied to the child and parents via the three basic concepts of this model: transpersonal care relationship, caring moment, and caritas processes.

\section{Transpersonal Caring Relationship}

The transpersonal caring relationship is the first basis for going to deep care known as the caring moment, with love and respect for all humanity (4). Looking at the family's past perceptions, her parents stated that the child was in a peaceful and happy family. It was seen that the child and her parents were tired and exhausted. The parents stated that the girl was nervous and had psychological problems due to the recurrent surgeries. The mother was tired of coming to the hospital all the time and the father was anxious. The parents were asked, "Can you inform us about your goals and expectations after leaving here?" for interaction. As a part of the transpersonal caring relationship, before the gastric transposition surgery, the parents and the child were supported via the efforts of the nurse, physician, and dietitian.

\section{Caring Moment}

The caring moment is the moment when two people with their own history come together and create a meaningful, authentic, and spiritual connection between them (4). The first maintenance moment started a bit unfavorably as

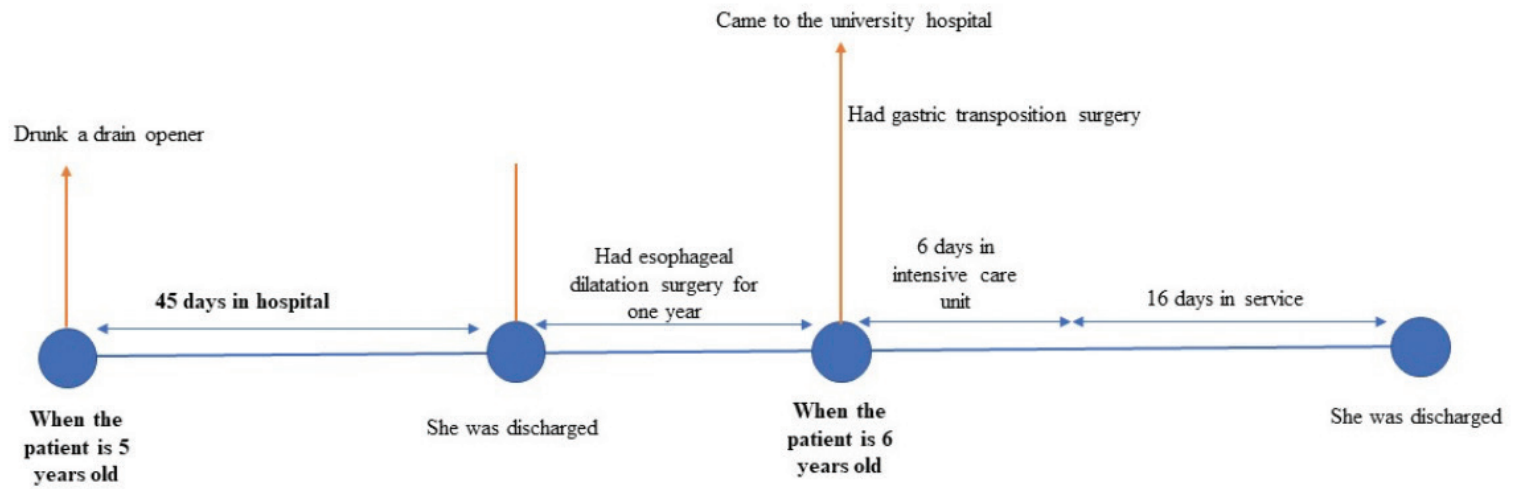

Figure 1. Timeline of the case according to Watson's Theory of Human Caring Model 
the child was contacted in order to apply an intravenous catheter. In the later moments of care, arrangements were made regarding nutrition, which is the most basic requirement in the perioperative period.

\section{Caritas Processes}

The caritas process is the essence of nursing and is a guide for nurses. These processes lead to the emergence of the healing and caring aspect of nursing. The caritas processes consist of 10 caritas factors (4). In this context, the evaluation of the child and her parents is given in Table I.

\section{Patient Follow-up and Outcomes}

In this case, there was a high level of anxiety in the child and the parents, as well as a sense of helplessness and guilt in the parents. The girl and her parents were supported by the perioperative caritas processes. The girl and her parents were observed in line with the nursing interventions. The result of this observation was evaluated both objectively (weight monitoring, respiratory sounds, and self-care requirements) and subjectively (parents' feedback). The parents and the child's self-confidence increased, they became happier and calmer individuals. While communicating with the nurse, they were more comfortable and were able to go into deeper issues. Before being discharged, the child wanted to be photographed with the nurse.

\section{Discussion}

This section is discussed over the three basic concepts of this model. These are the interpersonal caring relationship, the caring moment and the caritas processes.

This model has been used in the care of chronic diseases such as hypertension, chronic heart failure, and cancer which require long-term treatment in nursing (6-10). In this case report, this model was used for a child who had come 22 times into the pediatric surgery unit.

\section{Transpersonal Caring Relationship}

The transpersonal caring relationship involves the scientific, professional, ethical, aesthetic, creative and personalized giving and taking behaviors and reactions between nurses and patients. In this model, a holistic approach is used in the interpersonal care relationship (5). Based on this model, Aktaş et al. (8) were able to express the hidden feelings and thoughts with the interaction established in a case diagnosed with schizophrenia (9). In a study conducted on this subject in a pediatric intensive care unit, it was found that a unique relationship with pediatric patients was able to be established using this model (10). In this case, the nurse tried to establish a natural, sincere and authentic relationship with the child and the parents. The nurse asked the child and their parents to express themselves, share their experiences and express their expectations in order to evaluate this area. Thus, an attempt was made to establish a relationship of trust between the nurse, patient and parents.

\section{Caring Moment}

The caring moment in this model is the process of understanding each other between the caregiver and the care-recipient (4). Erbay et al. (7) highlighted a sincere, understanding and patient approach to those patients who experience hypertensive attacks by using this model in nursing care. In this way, the participation of the individual in nursing care practices was ensured (7). In this case, although the first care moment was negative, it turned into a positive situation when the nurse learned the expectations, beliefs and feelings of the child and her parents in the following days. Communication between the nurse and the child began to increase. This situation started to increase the satisfaction of the mother and father of the child.

\section{Caritas Processes}

The caritas process is the last step towards problem solving in this model. This improvement process consists of ten steps. Caring behaviors are used in this process. These are touch, sensitivity, active listening, eye contact, comfort, honesty, respect, trust, openness, and accessibility. In a case report, care behaviors such as touch, sensitivity, active listening, eye contact, comfort, honesty, respect, trust, and openness are accessible (4). Ten individualized care approaches were applied to ten individualized healing processes in the case of uterine atony according to this model. With the care given, it was observed that the mother's trust increased, her worries decreased and she took a more active role in the care of her baby (9). In this case report, the child and their parents were supported with a perioperative caritas processes. The child and her parents were observed in line with the results of nursing interventions.

The care given according to the Watson's Theory of Human Caring Model offers a different approach from the care given according to the medical model. This model reflects the essence of nursing. This model focuses on healing individuals with the concept of love and compassion. The care provided by Watson's caritas processes ensures that individuals are treated in a holistic way, and so it increases the satisfaction and safety of the individual. 
Table I. Nursing care applied to child and parents according to Watson's Theory of Human Care Model (Caritas Factors and Caritas Processes) (4)

\section{Caritas factors}

Formation of a humanisticaltruistic system of values (Embrace)

Instillation of faith-hope (Inspire)

Cultivation of sensitivity to one's self and to others (Trust)

Development of a helpingtrusting, human caring relationship (Nurture)

Promotion and acceptance of the expression of positive and negative feelings (Forgive)

Systematic use of a creative problem-solving caring process (Deepen)

Promotion of transpersonal teaching-learning (Balance)

Provision for a supportive, protective, and/or corrective mental, physical, societal, and spiritual environment (Co-create)

Assistance with gratification of human needs (Minister)

Allowance for existentialphenomenological-spiritual forces (Open)

\section{Caritas processes}

The child and her parents were approached with love, sincerity, understanding and patience. The nurse introduced herself. She then called girl by name. The opportunity to watch cartoons and play games was given in the perioperative period. Eye contact was made with the child to overcome the child's fear of nurses. Her mother and father were respected. She has been told that the growth curve of the girl is the same as her peers in order to reduce your parents' anxiety. Her parents were respected. Despite all the experiences, the importance of accepting the child and family as they are was explained.

The child and her parents were encouraged to ask questions about her disease to express her fears and thoughts, and were supported that he could achieve positive results if they cooperated with the treatment team. The girl was given the opportunity to play games with other children. Positive and reassuring communication was established with the child to express their concerns and fears. The girl stated that he wanted to go to the restaurant with her family to eat meatballs and potatoes after the operation. Both parents stated that they wanted the child to be fed like their peers and to stop repetitive surgeries. She was honored for the fears, desires and hopes of the child and family. For inspiration, they were introduced to the other child with the same illness and their family.

Her parents were told that they had to accept themselves spiritually, and then the current situation of the child. All the issues expressed by parents regarding the child's situation were approached sensitively and without prejudice. Play and cartoon, which is the child's interest, were used as a means of relaxation for the child. The results of the care given were treated with sensitivity.

The girl was afraid and angry that she could not heal and undergo recurrent surgeries. When she cried, she was not prevented from crying for relaxation. In a helpful and reassuring manner, parents' guilt was discussed. The trust of the nurse and the readiness of the nurse to help the patient and her family strengthened the relationship with the nurse. Support was provided for independence and individual freedom, not dependency on family and child.

The negative emotions experienced by girl and her parents due to non-healing and recurrent surgeries were listened. Parents' dream of being like their child's peers was discussed. It actively listens and ensures that energy passes through without being consumed by the feelings of others. The patient and her parents rested, emphasizing that the energies of parents and child should not be consumed by negative emotions. The importance of staying as "a family" despite the constant hospitalization was emphasized.

Perioperative self-care needs of the child (nutrition, dressing, hair combing) were explained to her family. Preoperative and juicy foods were explained. Postoperative feeding in the upright position, eating less or less frequently were emphasized. Equipment attached to the child was removed when he needed to dress and undress. To solve secretion problem, the child was given a semi-fowler position and cold steam. The patient was taught breathing and coughing exercises. Mobilization of the child in the service and intensive care unit was provided. For the comfort of the child, she wanted to watch TV cartoons. The intensive care unit was taken with the child's parents when appropriate. In the ward, time was arranged for the child to go to the game room for comfort. In the ward, support was provided for the patient to perform self-care needs. Continuity of those taught in intensive care was continued in the ward. It stated that the information taught to the child and her parents increases the trust of parents and the child and their anxiety decreases in both service and intensive care.

Girl and her parents were informed about the importance of oral feeding after gastric transposition. Information was given on excessive fat and spicy foods, and that foods that are too hard to digest should not be eaten, and that the bite was chewed well. It was emphasized that she should not eat at least two hours before going to bed at night. Her mother was told how to cook at home. Advice was given on how the child could alternatively give her favorite foods (making unseasoned baked potatoes instead of French fries etc.). I was told that the food at night should not be eaten. To prevent reflux, she was informed about how to lie in the semi-fowler position and how to give this position. In the learning-teaching process, they were helped to accept the information and readiness of learning and to accept others as they are and where they are.

In the pediatric surgery service, the nursing room is in the middle of the ward and is an audible and mobile place where treatment is prepared, patient acceptance, and visits. Therefore, the patient's room was identified as a quieter room away from the nurse's room. The bed linen of the patient's room was changed daily in the morning, and bathing was provided twice a week. The child's room was left clean after invasive and non-invasive procedures. During her stay in the intensive care unit, the child's self-care needs were met each morning and her linen was changed.

The child was helped with what she could do in her own care (issues such as oral care, oral aspiration). The equipment used in the care of the child (use of cold steam and aspiration device etc.) was explained to the girl. Favorite foods were added to the child's diet (such as banana, potato, meatballs). She was told to eat these foods without skipping meals and in small bites. An observation was made whether the child and her family made all these attempts.

The beliefs and hopes of the girl and the family were tried to be strengthened. The morale of the child and her parents was raised through the implementation of all process steps and trainings. Regardless of life, her parents were spoken about that what is essential in all situations is love and goodness. Despite all these difficult processes, it was talked to the child and their parents that every moment of life was full of goodness and love. The feelings and opinions of the child and her parents on this subject were also discussed. Here, the importance of love of family members for each other were emphasized.

*This table was created by the authors to show the nursing interventions made in accordance with the caritas factors in the Watson's Theory of Human Care Model 
The positive change, satisfaction and increase in harmony observed in both the child and the family as a result of the authentic relationship established in this case report show the effectiveness of the Watson's Theory of Human Caring Model. In addition, an example of providing holistic care in accordance with this model in pediatric surgery services is also shown. It is thought that this model will help nurses to determine the care needs of those children and their parents with corrosive esophageal injuries and to apply nursing interventions correctly. At the same time, maintaining this model-based care in all pediatric cases will help both the child and the parents to meet all their physical, psychological, emotional and spiritual needs and to provide nursing care in a holistic way. In-service training and courses should be organized to increase the awareness of nurses working in pediatrics and pediatric surgery services about nursing care based on Watson's Theory of Human Caring Model.

\section{Patient Perspective}

The patient and her parents were happily discharged. Her parents were happy that their daughter was in a good condition. The girl was happy that she could be fed orally. Communication with the nurses became more cordial for the child.

\section{Ethics}

Informed Consent: The approval concerning publication of case's treatment and follow-up period was obtained from patient's parents.

Peer-review: Externally and internally peer-reviewed.

\section{Authorship Contributions}

Concept and Design: N.G.Ö.Ö., F.V., Analysis and Interpretation: N.G.Ö.Ö., F.V., Literature Search: N.G.Ö.Ö., Writing: N.G.Ö.Ö., F.V., K.Y.
Conflict of Interest: The authors declared no conflict of interest.

Financial Disclosure: The authors declared that this study received no financial support.

\section{References}

1. De Lusong MAA, Timbol ABG, Tuazon DJS. Management of esophageal caustic injury. World / Gastrointest Pharmacol Ther 2017; 8:90-8.

2. Alser O, Hamouri S, Novotny NM. Esophageal caustic injuries in pediatrics: A sobering global health issue. Asian Cardiovasc Thorac Ann 2019; 27:431-5.

3. Pajnkihar M, McKenna HP, Štiglic G, Vrbnjak D. Fit for practice: Analysis and evaluation of Watson's Theory of Human Caring. Nurs Sci Q 2017; 30:243-52.

4. Watson J. Jean Watson's Theory of Human Caring. In: Smith MC, Parker ME. (eds). Nursing Theories and Nursing Practice 5th ed. Philadelphia, F.A. Davis Company, 2015; 321-39.

5. Gönen Şentürk S, Küçükgüçlü Ö, Watson J. Caring for caregivers of individuals with dementia: From the perspective of Watson's Theory of Human Caring. Journal of Hacettepe University Faculty of Nursing 2017; 4:62-72.

6. Costello M. Watson's Caritas Processes ${ }^{\circledR}$ as a framework for spiritual end of life care for oncology patients. International Journal of Caring Sciences, 2018; 11:639-44.

7. Erbay Ö, Yıldııım Y, Fadıloğlu Ç, Şenuzun Aykar F. Use of Watson's Theory of Human Caring in Nursing Care of Patients with Hypertensive Attack: Case Report. Turk I Cardiovasc Nurs 2018; 9:82-8.

8. Aktaş Y, Arabacı LB, Dülgerler Ş. Nursing care according to the Watson's Human Care Model in a patient diagnosed with schizophrenia: A case report. İzmir Katip Çelbi Üniversitesi Sağıık Bilimleri Fakültesi Dergisi 2020; 5:51-7.

9. Demirhan I, Tuncay Yılmaz S, Şahin S, Kaplan S. Nursing process in uterine atony cases according to Watson's Theory of Human Caring. Gümüşhane University Journal of Health Sciences 2019; 8:510-7.

10. Elbahnasawy HT, Lawend J, Mohammed EK. Application of Watson Caring Theory for nurses in pediatric critical care unit. IOSR Journal of Nursing and Health Science 2016; 5:56-67. 